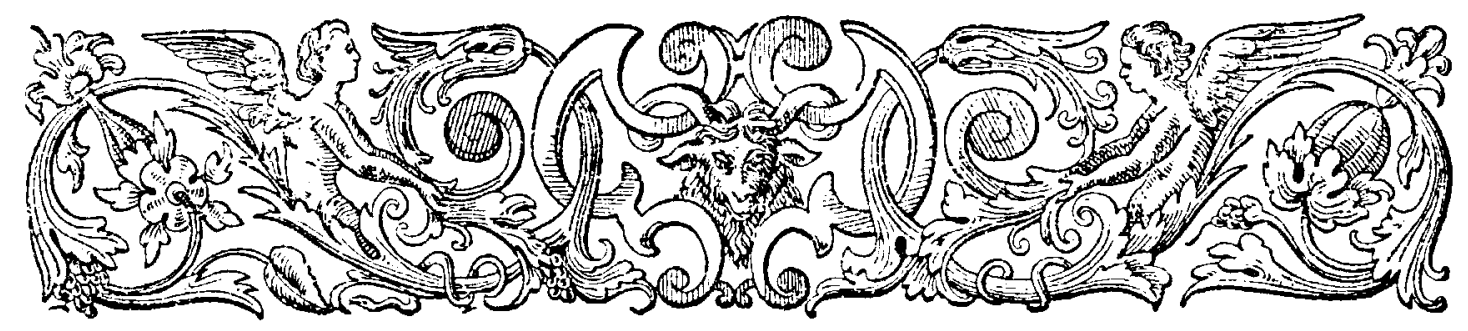

\title{
PASCHIER LAMERTIJN
}

(PASQUIER LAMMERTIN)

\author{
DOOR
}

JHR. DR. J. SIX.

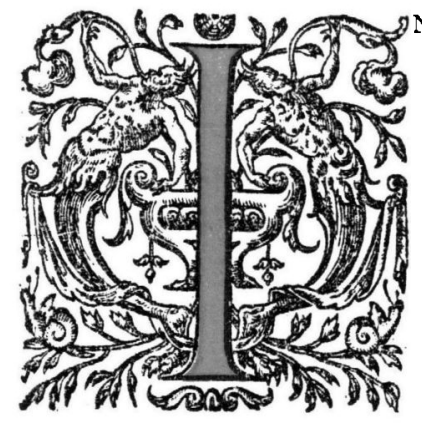

I 857 vroeg de Heer C. W. Bruinvis, terwijl hij een mededeeling omtrent Passchier Lammertijn in den Navorscher ${ }^{1}$ ) bracht of deze tijdens zijn uitvinding te Haarlem of te Alkmaar woonde. V.D. N. wees ${ }^{2}$ ), zonder deze vraag te beantwoorden, op de gegevens door DODT VAN Flensburg reeds in I $844-{ }^{\prime} 46$ in zijn Archief afgedrukt. In 1861 maakte de Heer BRUINvis in de Kroniek van het Historisch Genootschap nieuwe stukken bekend, in de Alkmaarsche Courant van 1893 , No. 51 , behandelde hij onder het hoofd „Beschermde Nijverheid”, nog door nieuwe bewijsstukken gestaafd, den steun aan dezen damastwever geboden en thans geeft hij in het IIe deel van het Nederlandsch Biographisch Woordenboek een korte schets van wat omtrent hem bekend is.

Die gegevens zijn vele, maar toch blijkt er niet duidelijk uit wat eigenlijk de uitvinding was waarvoor hem door de Staten van Holland octrooi werd verleend en, al wordt een enkel patroon vermeld, hoe zijn werk er uit zag.

\footnotetext{
1) VII (1857) blz, Io3 vraag $143 . \quad$ 2) T. a. p. blz. 347 .
} 
Nieuwe gegevens, die ik aan de vriendelijkheid van de Heeren BREDIUs, BRUINVIS en GONNET dank en de vergelijking met bestaande damasten hebben mij in staat gesteld, zoo niet zijn uitvinding zelve, dan toch haar werking, met meer kennis van zaken en dus billijker te beoordeelen dan ik vroeger heb gedaan, en vooral iets van zijn werk met zekerheid terug te vinden, hem andere patronen met waarschijnlijkheid toe te schrijven.

Ik meen het beste te doen zijn leven in tijdsorde te behandelen, van de reeds gedrukte stukken niet dan het noodige aan te halen, alleen die onuitgegeven bescheiden, die het verdienen in hun geheel af te drukken, en in den loop van het onderzoek de toeschrijving van zijn werk op de meest geschikte plaats in te lasschen.

PASquier Lammertin is geboren, blijkens een tweetal akten, een later te vermelden, en die waarin hij, 3 Febr. 1606, oud omtrent 43 jaren, ten behoeve van LODEWIJCK VAN DER HELST (de vader van BARTHOLOMEUS den schilder) over kweeperen getuigt, ') omstreeks I563, waarschijnlijk te Kortrijk, de hoofdplaats der linnendamastweverij, die daar reeds in de XVe eeuw bloeide en waar zijn "van” in de XIXe eeuw nog gevonden werd. ${ }^{2}$ )

$\mathrm{Hij}$ wordt reeds in $\mathbf{1} 593$ te Haarlem genoemd in een post van de thesauriersrekening van I593 (fol. 72): Betaald PASchIER LAMMERTIJN voor XLIX damastwerck tot iiij $£$ iij s. yder elle, van de Historie van DANIEL ten behoeve deser stad gecocht volgens d'ordonnantie ende quitantie iic vij $£$ xviij s. En hij woont daar nog 24 Januari I 597, wanneer CAREL LODEWIJCKSZ VAN DER HELST hem laat insinueeren over 25 grogreynen (sic!) 3 ) Hij zal daar toen waarschijnlijk reeds gewerkt hebben als een van de voortrekkers van de vele wevers, die daar tusschen 1595 en 1610 zijn saamgestroomd. Zooals de Heer BREDIUS mij mededeelde bevat het notarieel archief te Haarlem honderde akten van notaris WiLLEMS van tafellakenwevers en linnenwevers uit Vlaanderen afkomstig, maar ook uit Brabant en elders. Vooral uit Kortrijk komen zij, dan uit Gent, Wackent, Wackens of Wackene, ook uit Camerick, Weert, Nijmegen, Alebeeke, Rousselaer, Waerschot, Armentiers, Huyssen en Waernaerde bij Oudenerden, Meenene en Leegem bij Meenene, Halewijn, Boeckhoven, Gemert, Nieukerke, Geulichem, Thielt, Helmont, IJsegem, den Bosch, Breda, Geluwe en Sleysinge. Het spreekt van zelf dat dit niet allen damastwevers waren. Wel zou ik geneigd zijn hieruit op te maken dat AMPZiNG 4) zich vergist, wanneer hij den bloei der damastnijverheid in 1580

1) Notaris van Trier te Haarlem, medegedeeld door den Heer Bredius.

2) Vorsin, Messagier des Sciences et des Arts de Belgique 1. p. 296.

3) Notaris A. Willems te Haarlem, medegedeeld door den Heer Bredius.

4) Haarlem, blz. 340-I, 
reeds te Haarlem laat beginnen, op gezag van een rederijkersgedichtje van dat jaar, in de kerk, dat de weefkunst van BezaleEle, Ahaliah en de vrouw van TobIas prijst. Hij beroept zich verder op Hadrianus JuniUs, die in 1588 zijn Batavia uitgaf, maar deze roemt ${ }^{1}$ ) wel de witheid en fijnheid van het Haarlemsche linnen en de lichtheid en het duurzame zwart van het vryzeerlaken, maar spreekt met geen woord van gedamasceerde stoffen, terwijl hij zich toch zeker het genoegen niet zou ontzegd hebben in sierlijk latijn de figuren met die van de weefsels van Penelope of Helena te vergelijken. Wel wordt Oste Meeuwels, die Io Februari 1605 verklaart oud omtrent 55 jaar te zijn en sedert 1584 een huis in de Groote Houtstaat in huur bewoond te hebben, damastwerker genoemd, 2) maar in de aanteekeningen van de regeering van Haarlem van November I6I I waarin zij van verscheiden damastwevers allerhand patronen koopt, komt hij alleen met pavy voor. Omtrent damastweverij voor I 593 bewijst dit dus niets. Om zijn bleekerijen bezat Haarlem een alouden roem, linnenweverij was er blijkbaar ook, de damastweverij uit Kortrijk overgekomen vond er dus een dankbaren bodem. De Heer Bredius stelt mij in de gelegenheid b.v. ANDRIES ANDRIEsSEN te noemen, damastwerker van Kortrijk, die te Haarlem als getuige bij notaris Willemsz. voorkomt in 1597 en JACOB VAN DEN KERCKhoven, den 24 Aug. van dat zelfde jaar bij den zelfden notaris ook als damastwercker van Cortrijck, voor verschuldigd geld 3 damasten getouwen met 3 kammen en toebehooren in onderpand geeft.

DIRK BURger vaN SCHOOREL vermeldt in zijn Chronijk van Medemblik van I710, blz. 104 onder Alkmaar: "I 595 dient niet verswegen dat binnen Alkmaar een Perzoon genaamd PASQUier LAMmertijn heeft gevonden een Conste om in 't Linnen te weven, door trekwerk, allerhande Beelden, Historien, Veltslagen, ja alles wat iemand begeert, 't welk nooit te voren is gezien of gevonden, van welke konste hij van de Heeren Staten Generaal, Octrooi gekregen heeft voor ettelijken jaren."

BROUERIUS VAN NIDEK ${ }^{3}$ ) die in 1727 schreef, drukt zich voorzichtiger uit als hij, de plaats van de uitvinding in het midden latend, onder de beroemde mannen van Alkmaar noemt: "PASQUIER LAMMERTIJN een man van geringe geboorte maar fraaien geest, dit in het jaar I595 uitgevonden heeft de kunst van door trekwerk allerhande beelden, bloemen en figuren in 't linnen te weven".

VoISIN ${ }^{4}$ ) ik weet niet op welke gegevens, zegt van Kortrijk het volgende : „Il est probable que dans l'origine on n'y fesoit encore que les dessins, appelés

1) C. XVII p. 25 r.

2) Mededeeling van den Heer Bredrus.

3) Kabinet ran Nederlandsche Oudbeden 1 blz. 181 .

4) T. a. P. 
en flamand trek-werk; on n'aura inventé que successivement la manièrè d'y tisser des fleurs ainsi que des figures. Cet art fut singulièrementt perfectionné vers la fin den XVIme siècle. Un maitre tisserand de Courtrai nommé PAsquier LAM MERTiN, dont le nom existe encore en cette ville, s'estant retiré dans la Hollande, à cause de ses opinions religieuses, en I596, y obtint un octroi exclusif pour l'établissement d'une fabrique de damassé".

De datum van 1595, zal juist zijn. Het octrooi is in 1606 na den $3^{\text {den }}$ Juli 1) vernieuwd voor 6 jaar blijkens de aanvraag om verlenging van $16 I 3$ en is na 22 Februari 1601 reeds voor de tweede maal verleend. ${ }^{2}$ ) Er was bij de eerste vernieuwing van het octrooi blijkbaar dezelfde twijfel gerezen, dien men bij VoIsIN tusschen de regels leest en dien Dr. JAN KALF ${ }^{3}$ ) onverholen uitsprak : or de vinding van LAMMERTIN wel een nieuwe was en niet de uit Kortrijk overgebrachte kunst van linnendamast te weven. Het kan zeker geen twijfel lijden dat er voor 1595 linnen damasten geweven zijn. Weldra zal ik er verscheidene bekend maken in Het Huis, die in niets onderdoen bij het knapste wat LAMMERTIN heeft geleverd en daaronder zelfs een XVe eeuwsch patroon.

Op de damasten afgaande lag dus die twijfel voor de hand. Toch is er geen reden aan de waarachtigheid te twijfelen der verklaring 22 Februari I60I onder eede in handen der regeering van Haarlem afgelegd door de ,gesworen waerdeyns van den taffellaekenen, servietten ende alrehande damastwercken" te Haarlem, "Pieter van ACkeren en ANdries van Haelbergen, beyde Coopluyden in linnenlaekens ende servietten, mitsgaders JACOB Denys, GHysel AdINGH ende Antonis van den Putte..... dat bij Paschier Lammertijn gemaect was een serviet ons verthoont daer inne stont 't wapen van zijne Excellentie met sijne quartieren, ende andere wercken, seer constich gewrocht, sulx dat sijluyden noyt diergelijcke hadden gesien, als noyt bij heure kennisse alsulx in dese provincie gemaect geweest zijnde". 2)

Maar in de laatste woorden schijnen zij wel een slag om den arm te houden en wij worden er in elk geval niet veel wijzer door. Wel door de beide verklaringen door notaris ADRIAAN WILLEMS te Haarlem, 3 Juli 1606 voor de derde aanvraag in gereedheid gebracht. 4) Daar verklaren Joos' COUDTIJSER, JoOsT VERHAGEN en JOOS VAN BAELBERGEN, mannen van 73, 7 I en 67 jaren, ,alle van Curtrijck, wonende binnen Haarlem, dat zijluyden van heure jonge jaeren den ambacht van damastwercken geleert, ende daernae den coophandel van dien lange jaeren gedaen hebben; .... ende dat zijluyden alle, gelijck op huyden, gesien ende beschouwen hebbende

1) Kroniek van het Historisch Genootschap XVII (186r) blz. 46.

2) T. a. p. blz, 45 .

3) Versiag van het St. Bernulphusgilde over 19ro. blz, XXXIX.

4) Medegedeeld door den Heer Bredius. 
den cammen, simpels, patronen ende wercken van de stucken damasten, daerop den yoorsz. PASSCHIER zijn tweede octroy vercreegen heeft, met goede waerheyt ende zeeckerheyt connen verclaeren ende getugen, als zij verclaeren ende getugen bij dezen, dat de voors. wercken nyeuwe inventiën zijn, als sulcx voor desen noeyt gesien noch gehoort hebbende" en ten zelvendage JoOs BosTyNS, damastwercker en Anthonis Hugaert, beiden 58 jaar oud en "van Curtryck", Bostyns, "dat hij den handel van damastwercken den tijdt van XL jaeren lanck gedaen, maer noeyt voor desen gesien heeft alsulcke wercken, als tegenwoordich by den voorsz. PASSCHIER zijn gepractiseert, ende hij zijn tweede octroy op vercreegen heeft, ende sulcx voor de waerheyt getugende is, dat dezelve zijn : nyeuwe inventiën noeyt te vooren by yemande gemaect noch gevonden, daer hy af gehoort heeft"; HUGAERT, „dat hy 't ambacht van zijdedamastwercker ten tijdt van twintich jaeren gedaen, maer ook noeyt voor des gesien heeft alsulck of diergelijcke wercien als den voors. PASSCHIER heeft gevonden ende gepractiseert; ende sulcx dezelve houdende is voor een nyeuwe inventie".

Het blijkt daaruit, dunkt mij, dat wij met een technische vinding te doen hebben, die den uitvinder in staat stelde breede patronen, zooals wij van hem zullen leeren kennen, op eenvoudiger wijze dan zijn voorgangers uit te voeren. Hoe hij dat deed blijkt niet, maar dat zooiets bij een handweefgetouw zeer mogelijk is kan men lezen in het XVe, XVIe en XVIIe hoofdstuk van LUTHER Hooper Handloom-zveving waar diergelyke uitvindingen besproken worden. Een tipje van den sluier, die zijn geheim bedekt, wordt echter opgelicht, door de volgende Haarlemsche akte, die de Heer BREDIUS mij mededeelde:

"Op huyden compareerden voor mij openbaer notaris, ten bijwesen van de nabeschreven getuygen, d'eersame GUILLIAEME DE CUIJPERE, out omtrent 58 jaeren ende ANDRIES PATIJN, brandewijnbrander, out omtrent 53 jaeren, deser stadts poorteren, ende hebben bij hunne mannen waerheyt in plaetse van eede ten versoecke van PASSCHIER LAMMERTIJN, damastwercker, rechtelicken daartoe verdaecht zijnde verclaert ende geaffirmeert, dat op voorleden Dingsdage den eersten deser maent Augusti, zijluyden getuygen door begeerte van de voorsz. PASSCHIER LAMMERTIJN ten huyse van hem, ANDRIEs PATIJN, ontboden hebbende den persoon van PIETER VAN DEN CASTEELE, denzelven hebben verhaelt ende aengeseyt, dat hij PASSCHIER verstaen hadde, dat bij hem, PIETER, dagelix gearbeyt werd soo in 't schilderen als weven directelicken tegens sijns PASSCHIERS vercregen octroye, doch dat hij PASSCHIER geene onvreede begeerden maer gaerne vruntelicker wijse met hem wilde verdragen, ende naer zijluyden metten anderen daerover in propoosten waeren geweest ende den voorsz. Pieter van de Casteele verclaert hadde met hem, Passchier, oock nyet anders als vreede te begeren ende gaerne met hem van gelijcken in eenicheyt 
te willen accorderen, sijn ten selven tijde aldaer ten huyse mede innegecomen den persoon van JAN DE CONINCK ende eenen jongman met een blancke baert, wiens naem zijlieden niet en kennen, ende naer denselven CONINCK ende jongman den voorsz. PIETER VAN DEN CASTEELE in 't voorhuys ontboden en met hem gesproken hadden sijn zijluijden alle beyde metten zelven PIETER gecomen in 't geselschap van hen deposanten ende sulx tusschen henlieden van de zaecke van de voorsz. PAsschier ende hem PIETER propoosten vallende, hebben den voorsz. JAN DE CONINCK ende de jongman opentlijck geseyt ende tegen hen getuygen verhaelt, dat zijlieden de saecke van den voorsz. Pieter van de CASTeEle als heurluyder medebroeder dien zijlieden nyet verdruct en wilden hebben defenderen ende hem uyten naeme van den Buyck 1) van de damastneringe alhier ter steede souden voorstaen, ende dat zijlieden ten dyen fijne hen aldaer ten huyse van hem, ANDRIES PAtijn, mede presenteerden off gelijcke woorden in effecte, oock daer bij voegende dat den Heeren Burgemeesteren deser stadt henlieden daertoe wel souden assisteren. Seggende voort den voorsz twee getuigen, mitsgaders JACOBCORNELISZ BASTERTPIJP. capiteyn van de schutterij deser stadt, out omtrent $5 \mathbf{1}$ jaeren, mede voor mij notaris ende getuygen comparerende dat s'anderen daechs als Woonsdage den voorsz. PASSChier Lammertijn metten voorn. Pieter van den CASTEele vergadert zijnde ten huyze van hem, BASTERTPIJP, omme metten anderen te spreken tot accordt van hunne quaestien, sijluyden getuygen alle drye alsdaer mede over geroepen wesende den voorsz. PIETER VAN DEN CASTEele op ' $t$ affragen van den voorsz. Passchier Lammertijn onder veele andere propoosten die tusschen hen vyelen, hebben hooren bekennen, dat hij, Pieter, ten tijde hij in hem Passchiers dienste was arbeydende hem PASSCHIER ontnomen hadde, twee off drye van sijne papieren. Ende dat hij noeyt over hem PASSCHIER aen die van de neeringe van de damasten clachtich was geweest, maer dat hij bij die van de neeringe selffs versocht was.

Overbodich staende zij deposanten desen t'allen tijden des nodich ende versocht naerder met eede te starcken. Ende concenteerden hiervan bij mij notario gemaeckt ende aen den requirant gelevert te werden een oft meer acten in forma.

Aldus gedaen binnen Haarlem ten huyse van de voorsz. BASTERTPIJP inde Smeedestraat, den 7 den Augusti anno $\mathbf{1 6 0 6}$, in presentie van Pieter Boudewijns LEeUw ende Pieter Cornelisz Visscher, roedragers deser stadt, als getuygen hier toe versocht die metten deposanten den bewerpe hebben geteeckent.

In waerheyts oirconde desen bij mij openbaer notario bevesticht, W. VAN TRIER, notarius publicus."

1) Buyck in de beteekenis : Corpus. 
. 


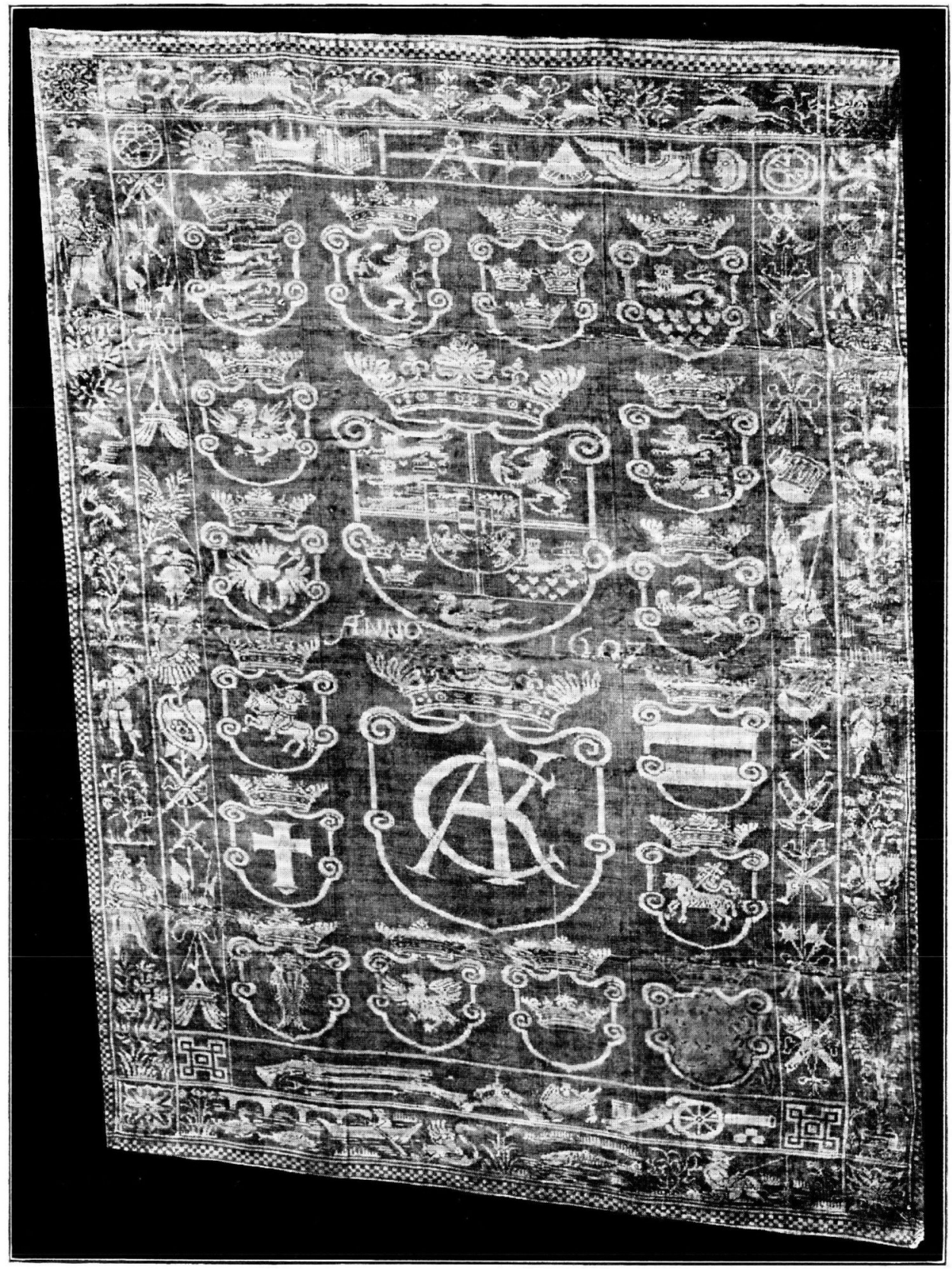

Fig. 2. SERVET VOOR KONING CHRISTIAAN IV VAN DENEMARKEN, geweven door Paschier Lamertijn. 1602. Verz. Six. 
Hieruit blijkt dat aan de geschilderde papieren patronen evenzeer als aan het weven iets bijzonders moet zijn geweest, waardoor het trekwerk op deze damasten kon ingericht worden. Hoe, dat ontgaat mij.

Veel goedkooper werd het werk er nog niet door, dat zal men zien uit de vergelijking van zijn prijzen met die van smalle patronen van gefigureerde damasten, daar zij twee, drie, tot negen en een half maal duurder zijn, al blijft het mogelijk, dat zonder zijn uitvinding het verschil nog grooter zou geweest zijn.

Den uitvinder is het dan ook, trotsch alle bescherming, slecht vergaan.

Het was anders toch wel knap werk wat hij leverde en dat de aandacht is blijven trekken. Wij vonden reeds vermeld een serviet „daer inne staat ' $t$ wapen van sijn Excellentie met sijne quartieren ende andere werken'. De heer BREDIUs vond te Haarlem een acte van notaris van TRIER van 6 Aug. 1603 , die aldus aanvangt: "Op huyde compareerden voor mij openbaar Notaris bij den Hove van Hollandt geadmitteerd, tot Haarlems residerende, in bijweesen van nabescreven getuygen, d'eersame Passchier lammertijn, damastwercker, out omtrent XL jaren en HaNs TOEBast, out omtrent XXVII jaren, ingesetenen deser stadt, ende hebben ten versoecke van ABRAHAM VAN SUYT, damastwercker, verclaert en geaffirmeert warachtich te wesen : te weten de voorsz. PASSCHIER LAMMERTijn, dat omtrent vyer maenden geleden sonder den juysten dach onthouden te hebben sij getuygen aan de (voorseyde) ABRAHAM VAN SUYT vercocht gelevert en den zelven ABRAHAM hem oock voldaen en betaalt heeft seeckere elff servieten damastwerck van wapenen van Nassauwen, die naderhand bij den selven ABRAHAM ter bleecke gelevert zijn aan WILlEM AELBRECHTS, bleecker tot Heemstede" enz. Hoe verder dan deze servetten ter bleek gestolen zijn, behoeven wij niet met de uitvoerigheid van den notaris te verhalen. Onze wever teekent PASSCHIER LAMERTIN.

In 16 I I verkoopt hij nog, zooals wij later zien zullen : „twee douzijn servietten van 't wapen van Nassau' tot den eenheidsprijs van twaalf kwarts voor 9 p.-10 s.per el, of $f 4.75$ per stuk, aan burgemeesters van Haarlem.

Een eeuw later, in I 7 I, legateert volgens akte van notaris C. WINTER te Amsterdam, juffr. GeEsteranus "een damast tafelkleedje daar $160 \mathrm{I}$ in geweven is met verscheyde wapens daerbij."

Dit patroon, met het jaartal en de wapens, komt ook thans nog in enkele stukken voor, die als zeldzaamheden bewaard zijn. In de Ige eeuw moet er een aan Z. M. Koning WILlem III geschonken zijn. Mevrouw O. P. bezil een ander en een linnenkoopman liet er mij een zien, dat hij, met twee halve stukken, in een klooster gevonden had. Ik zelf kocht er een te Valkeveen met het jaartal I604, afgebeeld in Het Huis 1908 pl. XXX, waarnaar wij het hier, met de vriendelijke 
toestemming van den heer EdUARD CuYpers als Fig. I herhalen. Mr. TH. S. liet mij een exemplaar zien van $\mathrm{I} 605$ ! het is reeds beschreven in Het Huis, waar ik uit het wapen van Haarlem mocht afleiden dat het een Haarlemsch weefsel was, wat door de akten volkomen bevestigd wordt en in Oud-Holland XXVIII (19I0) blz. 20, waar ik het met de randen, om de visschen en krabben van QUIRIJN JANSZ DAMAST, niet geheel zonder reden, in verband bracht.

Toch meen ik het mijn lezers gemakkelijk te maken door die beschrijving te herhalen:

Servetten: 1. 97-I00 ( $\left.1 \frac{1 / 2}{\mathrm{el}}\right)$, br. $70(4 / 4)$, zeer fijn damast

rand: boven. I. De gekroonde wapens van Gelderland, Holland, Zeeland, Utrecht, Friesland, Zutphen, Ojerijsel, Groningen. II. Hazewinden jagen een zwijn, een hert en hazen tusschen de struiken; in de hoeken: ornament. III. Zon, scheepsromp, bijbel, rechthoek, passer, sterren, zwaard, graadboog of zonnewijzer, maan ; in de hoeken : wereld- en hemelbol. Onder. III. haakbusschen, onduidelijk instrument, kruidhoorn, kanon; in de hoeken: rechtlijnige versiering. II. Waterplanten en lange brug waarvoor: eend, visch, roeier, verder zwaan, visch en hengelaar; in de hoeken : ornament.

I. LOF - GOD - IN - WIENS - HANDEN / HIER - ALLE - GHEWELT • STAET / HII - WAECT - OVER - ONS - LANDEN / DOOR . EDELER • STATEN • RAET • daarnaast EN • DOOR • DE - LOFLICKE - DAET / DES - NASSOUWEN - VOL - EEREN / MET - EENDRACHTICH • SAET / CLEINE - SAKEN • VERMEEREN •

Daarnaast het wapen van Haarlem. Terzijde links, I. Valkenjacht, boven elkander jagers en boomen en reigers door een valk aangevallen, II. Wapentropheeën; rechts, II. Wapentropheeën, I. Boomen en jagers; patroon: Aan een afgehouwen stam, waaronder TANDEM - FIT - SURCULUS - ARBOR, een kleine loot en een opgeschoten vruchtdragende oranjeboom, waarin het wapen van Prins MAURITS VAN NASSAU, waar naast links : $\dagger \mathrm{JE} \cdot$ rechts : MAIN TIENDRAY $\cong$ links: † NASSAU $\times$, onder ANo I60I - I604 of I605 • links en rechts 8 kwartieren : 1. (heraldische r.) Nassau, Hessen, Stolberg, Coninckstein ; r. Saksen, Mecklenburg, Conincksteyn (ten onrechte in plaats van Hessen) Saksen.

In Oud-Holland heb ik reeds gewezen op de servetten van $\mathrm{I} 602$ van Koning Christiaan IV van Denemarken en zijn gemalin ANNa Katherina van BrandenburG, gehuwd in I 598, die om den zelfden stijl en geheel de zelfde rand, zeker ook van LAMERTIJN zijn.

Ik geef een nieuwe beschrijving ter verduidelijking van Fig. 2.

Servetten 1. $96\left(\mathrm{I}^{1 / 2} \mathrm{el}\right)$, br. $70(4 / 4)$, zeer fijn damast. 
Mijn verzameling, Nederl. Museum, Museum te Kortrijk, uit de veiling SchulmaN, 's Gravenhage 9-I I-I907.

rand als de servetten hierboven beschreven met uitzondering van I boven en onder. Daardoor zijn terzijde zoowel I als II hooger en met meer figuren.

patroon: In het midden het gekroonde wapen van Koning CHRIstiaAN van Denemarken. I Denemarken, II Noorwegen, III $Z$ weden, IV Gothen. Punt: Wenden; hartschild, I Sleeswijk, 2 Holstein, 3 Stormarn, 4 Ditmarsen. Klein hartschild, r. Oldenburg. 1. Delmenhorst. Daaronder ANNO I602. Daaronder een zelfde gekroond wapenschild met een monogram, samengesteld uit $\mathrm{C}$ en $\mathrm{A} K$, de letters van den Koning en zijn gemalin. Rondom 16 wapenschilden, boven de vier kwartieren van het wapen, dan rechts (heraldisch) het wapen van de punt, verder afwisselend links en rechts de vier kwartieren van het hartschild en de twee helften van het kleine hartschild, eindelijk links : . . . . onder: IJsland, . . . . ? . . . . . ? en een blank schild.

Heeft LAMERTIJN dit werk op bestelling gemaakt of in de hoop op verkoop aan de Koning of aan de Staten tot een geschenk? Wie zal het zeggen. Maar ik zou geneigd zijn aan zijn eigen onderneming te denken, wanneer ik van deze zoo uitvoerige heraldiek de tegenhanger vindt in een servetje van den Rev. C. H. Evelyn White, Photo van het Victoria and Albert Museum 26400-206, Fig. 3, dat geheel zijn hand schijnt te verraden.

De beschrijving heb ik gemaakt met behulp van Proceedings der Society of antiquaries XIX (1902) p 86 Servet 1. $37^{1 / 2}$ inch. $=94$ c.M., br. $27^{1 / 2}$ inch. $=69$ c.M. (4/4).

Rand rondom enkel blokjes.

Patroon. In het midden het overvolle Engelsche Koningswapen (I I en 4 Engeland, 2 en 3 Frankrijk; II I EDward the Confessor, 2 ST. EDMUnd of ST. Oswijn, 1) 3........., 4 ST. EDward Martyr, hartschild, Noorwegen; III Rome; IV I .........., 2 Koning ARthur ? 3 Koning ARTHUR, 4 St. JorIs. Punt: Ierland ; hartschild: Wales, gedekt door een koningskroon en omgeven door de kousenband, waarom onder een lint met SEMPER EADEM en gehouden door een leeuw en een draak. In de hoeken de wapens van Engeland, Frankrijk, ST. JoRIS en Schotland met koningskronen gedekt. Daar tusschen in afwisselende rij Engelsche rozen en Fransche leliën, onder koningskroontjes en onder de bovenste wapens: ANNO + I603 INDE - 4 . DE MAENT.

Het doelt blijkbaar op het begin der regeering van Koning JACOBUS I, die in de 4de maand van 1603 , Koningin ElisabeTH, 3 April gestorven, in Engeland opvolgde. LAMERTIJN die, naar wij bij AMPzING, blz. 342 lezen, in I606 ook het

1) Of kan het soms Zweden zijn? 
allertijnste linnen tegen den hoogsten prijs kocht, en dus waarschijnlijk ook koopman was, ging in dat jaar naar Engeland, zeker om zaken aan het Hof te doen, vooral om ook daar octrooi te verkrijgen, misschien wel om zich daar te vestigen. Hij verkreeg 26 Augustus 1606 van de Generale Staten de volgende resolutie: 1) "Opte requeste van PASChIER LAMMERTIJN, is geappoincteert, dat de heren Staten Generaal goetgevonden hebben, den suppleant $t$ 'employeren, omme in Engelant te brengen, in handen van den agent $C_{A R R O N}$, een casse met damastwerk, die deselve CarRoN gelast is te presenteeren aan den prince VAN WALLIS etc."

Maar men kreeg argwaan en 30 October daaraanvolgende werd besloten: 1) „Goetgevonden, dat men duplicatie van de depesche die PASCHIER LAMMERTIJN, reysende naer Engelant is medegegeven aen den prins VAN GaULIS ende den agent CARRON soude senden ende voorts aenscrijven, dat hij voor deselve LAMMERTIJN geen octroy en procurere bij den Coninck, dat d'ingesetenen deser landen zou zijn prejudiciabel."

Hij keerde dus terug zonder in Engeland een nieuwen werkkring gevonden te hebben, al had CARON van zijn waar een ruim gebruik gemaakt tot geschenken, zooals uit de resolutie van 29 December 1606 blijkt:

"Is Paschier LAmmertijn, damastwerker tot Haarlem, geaccordeert ordre op 2092 p. IO $s$. in betalinge van alsulk damastwerk, als den agent CARRON in Engelant gehouden heeft, omme aldaer aen eenige heeren te vereren, volgende desselfs recepisse, gedagteekent 19 Oct. 1606."

Daarin zal het damast van Prins HeNdrik van Wales, een i 2 jarigen knaap, inbegrepen zijn geweest.

Maar de klandizie van het Engelsche hof zal hij evenmin gekregen hebben als het begeerde octrooi. Het tafellaken van JACOBUS I, van I609, nu van Mrs. OweN Gould, (Photo Victoria and Albert Museum 32299-206) lijkt mij Kortrijksch en voortzetting van den stijl van dat van ELISABETH, (Het Huis 1913), en geheel het zelfde geldt van het tafellaken van KAREL I als prins van Wales in 16I7, (Victoria and Albert Museum Photo 32237-795), al lijkt de rand Haarlemsch. Van Paschier LammertijN zijn zij niet, zoover ik zien kan.

Veeleer zou dat mogelijk wezen van een servet van LADy ANCASTER, (Phot. Victoria and Albert Museum 32375-206), dat een Haarlemsche rand heeft om een veld met gezaaide bloemen en wapens van een echtpaar van hoogen Engelschen adel: IOHNE MAITLAND L(ord) THIRLESTAN, - later eerst Viscount dan graaf LAUNDERSDALE, - en D(ame) ISABEL - SETONE, dochter van den graaf VAN DUNFERNLINE, vóor 1610 gehuwd, maar het eigenaardige van het werk dat wij tot nog toe van hem zagen, het geheel ontbreken van rapport, missen wij 1) Dodt van Flensburg IV 126. 
hier en ook de rand heeft niets dat aan LAMERTIJN herinnert, komt integendeel geheel overeen met die van Quirijn JANSz. DAMAST als in de onderrand van de MARIA Boodschàp, en de wapens zijn ingevoegd op de wijze zooals deze het in den Orpheus deed (Oud-Holland XVIII, I9Io, Fig. 5 en 4).

Wel had PASCHIER in Holland zijn tweede octrooi gekregen en nu wendde hij zich tot Alkmaar om daar de ondersteuning te vinden, welke hij niet missen kon. "Hij biedt 4 Maart 1607 aan de stad Alkmaar aan zich aldaar te vestigen en zijne kunst te opereeren en die deelachtig te maken aan eenige daartoe door burgemeesteren geschikt geachte personen, mits men hem voor omtrent 6 jaren renteloos leende $f 3000$, vrije woning in de brouwerij van het St. Elisabeths gasthuis verschafte en eenige jongens uit het weeshuis of anderen bij hem besteide." 1)

De regeering der stad, naijverig zeker op den bloei der Haarlemsche damastweverij, gaat daar grif op in en sluit reeds den volgenden dag een contract 2 ) waarbij PASQUIER LAMBERTIN zich verplicht "zijn handtwerck ende conste" te Alkmaar uit te oefenen, waarvoor hij een renteloos voorschot krijgt van $f 3000$, op voorwaarden, die men in het stuk zelve mag nalezen, evenals de nadere zekerheid die hij ten gevolge daarvan der stad bij schepenkennisse van 7 Juni 1607 op zijn huis geeft. ${ }^{3}$ )

Wij stippen er alleen nog uit aan, dat hij tusschen beide datums voornemens was naar "Francryck" te reizen en dat zijn kinderen reeds in staat werden geacht hem bij overlijden te vervangen.

Eerst had hij nog werk voor Engeland en wel van het allerduurste, dat hij gemaakt heeft, driemaal zoo hoog in prijs als de servetten van Prins MAURITS later zijn. Het bovengenoemde servetje, veel eenvoudiger van arbeid, kan, hoewel op bestelling gemaakt, hier dus zeker niet in aanmerking komen. Voor 23 November 1607 is de resolutie die de betaling regelt:

"Is PASCHIER Lammertijn geaccordeert ordonnantie van 712 gl. voor een ammelaken damastwerck, drye ellen breet, zes ende anderhalf quaert lanck, twee dozijn servieten, twee banquet servieten ende twee schietdwalen, tsamen 22 ellen 3 viersdeelen, tot $30 £$. d'elle, welck linnenwaet in Engeland bij den agent CARoN ten dienste van den lande is vereert". ${ }^{4}$ )

Er zijn daarin of nog 30 gld. algemeene kosten of men moet voor 22, 23 ellen lezen.

Gemakkelijk was het evenwel niet tegen f ro de vierkante el, een ongeloofelijke prijs als men de waarde van het geld in aanmerking neemt, afzet te

1) Alkmaarsche Courant 1893 no. 5 I.

2) Kroniek Van het Historisch Genootschap XVII (186I) blz. 47.

3) T. a. p. blz. $4^{8}$.

4) Dodt van Flensburg V. blz. 5 . 
vinden en spoedig beginnen zijn verzoeken aan Alkmaar om hulp. I6 Januari 1608 is het maar een kachel in de werkplaats in het gasthuis, die de stadsregeering weigert te koopen, alleen de kosten van stellen wil zij dragen, als hij zelf die verschaft 1), maar 5 Augustus zit hij met onverkochte weefsels verlegen en de stadsregeering wil die voor $f$ I 200 niet koopen, wel wordt hem toegestaan die som van de stad te leenen ${ }^{2}$ ) mits tegen voldoend pandschap en niet langer dan voor 3 jaar. ${ }^{3}$ ) Men hoopte blijkbaar deze rekening vereffend te zien voor den afloop van het contract. Alkmaar had niet den moed of miste de middelen om de onvermijdelijke gevolgen van bescherming te dragen en waar er geen werk was, dit te verschaffen.

Het zijn de Staten weer die helpen. 24 Juni 1609: „Is gedepescheert ordonnantie voor PASCHIER LAMMERTIJN, damastwerker, voor de somme van $6480 £$, voor twee hondert seventich ellen fijne damaste lynewaten, tegen $24 £$. d'elle, bij haar gelevert, daermede de heren ambassadeurs van den Coninck van Vranckrijck en Groot-Britannië bij de heren Staten zijn doen vereren". 4) Ook dit damast, zeker ook 12 kwarts, dus nog voor zeer hoogen prijs. Maar toen in het begin van het volgend jaar een geschenk aan SPINOLA zou vereerd worden, achte men de $f 24$ en $f$ I 5.- die LAMMERTIJN vroeg, al erkende men dat zijn werk was "so fijn ende wel in poincten dat men die eere van het land daermede zal mogen bewaren", te hoog en werd de waarde door deskundige vrouwen op $f$ 20.- en $f$ I2.- getaxeerd. Hoeveel ellen gekocht werden met de $3675 \mathrm{gl}$, Io st., die hem werden uitbetaald, blijkt echter niet. ${ }^{5}$ )

De toestemming, 20 Juni 1610 verleend tot het aanplempen ter wille van een toegang tot zijn woning ${ }^{6}$ ), behoeven wij niet te vermelden.

Uit het Register van Cautièn van I6I I teekende de heer BREDIUS aan dat PASSChYER LAMBERTIJN, damastwercker, wonende te Alkmaar, groote zaken en met groote sommen deed; nadere bijzonderheden heb ik daarover niet.

De ruimste gegevens voor de kennis van zijn werk geeft de aanteekening "no. 2168 Inventaris 2e Afd. van het Haarlemsche gemeente archief”, door den Heer J. C. GonNET gevonden, die ik in zijn geheel als bijlage geef, naar het net, want het ook bewaarde klad heeft te onbeduidende afwijkingen om die ook af te drukken.

"Coope van Damastwevers, I6II" staat er buiterop. Burgemeesteren van

\footnotetext{
1) Alkmaarsche Courant t, a. p.

2) Alkmaarsche Courant t. a. p.

3) Ned. Biogr. Woorderboek II. PAschirr LAMMERTIJN.

4) Dordt van Flensburg V. blz. I3.

5) Dordt van Flensburg $V$ blz, $6, I_{3}$ en I4 Januari r6ro.

6) Alkmaarsehe Courant t. a. p.
} 



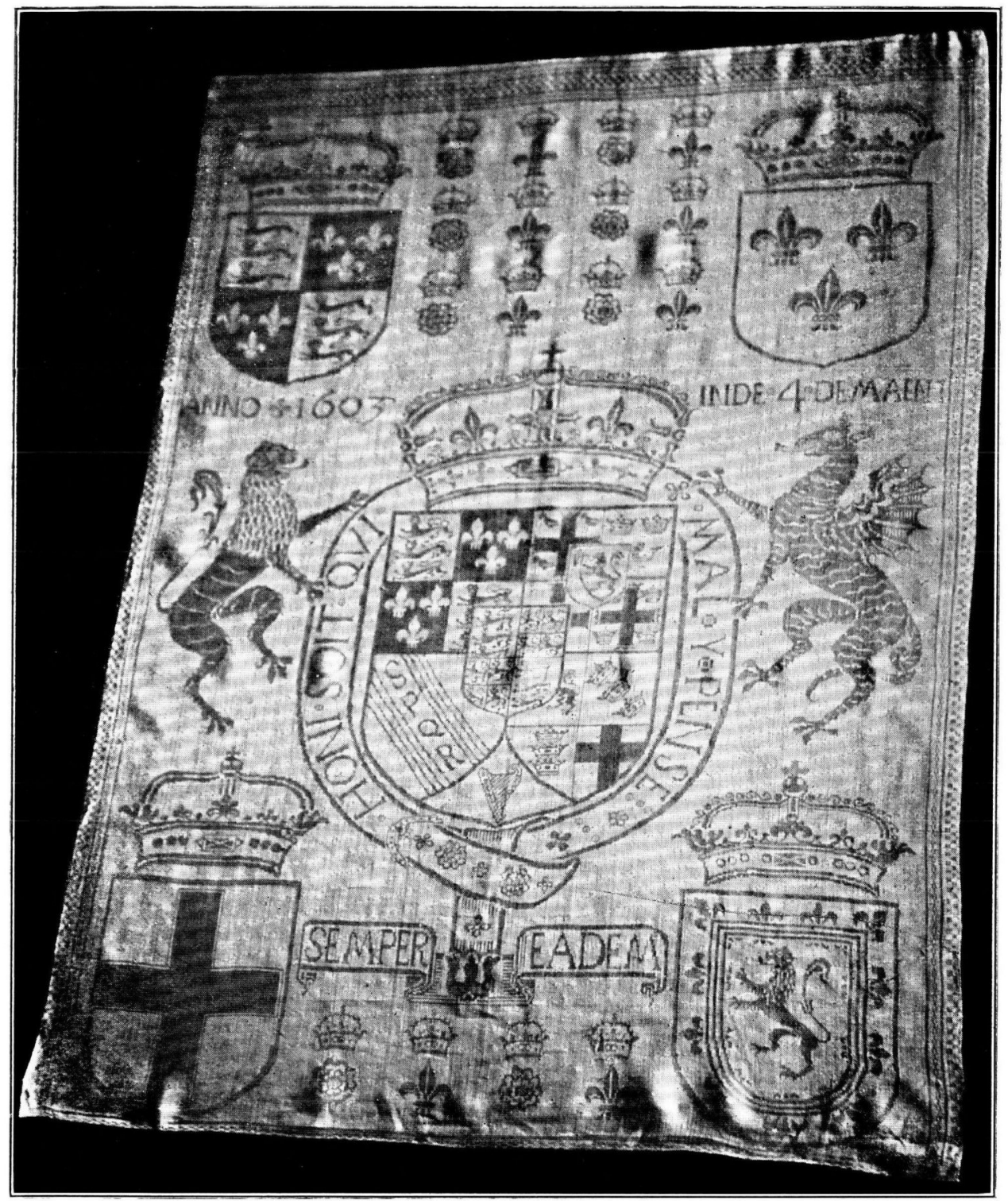

Fig. 3. SERVET VOOR KONING JACOBUS I VAN GROOT-BRITTANNIE, geweven door PASChIER LAMERTIJN. 1603. Victoria and Albert Museum. 
Haarlem kochten onder leiding van Burgemeester MAERTEN RUYCHAVER op I I, I 2, I 3 en I4 November I6I I voor 10178 gulden I 5 st. 9 d. tafellinnen van verschillende wevers. $Z$ ij deden dit in opdracht der Staten Generaal, die met het gekochte de juist in het land gekomen „twee Vrouwen Princesse van CondÉ ende de Princesse van ORANGIEN" vereerden. ${ }^{1}$ )

Behalve eenige bloempatronen zijn het meest weinige tafereelen met figuren, die ons grootendeels ook uit den boedel van QUIRIJN JANsz DAMAST van 1650 bekend zijn. Hij zelf komt hier ook reeds voor met "zeevaert", wat in zijn boedel als "schipvaert" "scheepkens", „schepen" vermeld staat, een patroon waarvan ik altijd vage berichten verneem, maar dat ik nooit te zien kan krijgen, met een "bloempje" en met "de historie van 't land van belofte", ook wel „Landt van belofte ofte Josue en CALEB", terwijl het bij Olivier DE GRAEF, die het ook levert: "Josue en CALEB in 't land van belofte" heet. Eer dan aan het patroon, hier vroeger als Fig. 6 gegeven, ben ik geneigd aan een ander te Stockholm te denken, dat een soortgelijken rand heeft als de "Historie van Troyen”, hier door Jaques Lammertijn, ${ }^{2}$ ) misschien de broeder van PASchier, en MiChiel ENGels geleverd, niet door QUIRIJN JANSZ. in wiens boedel het ook voorkwam. Dit zelfde geldt ook voor de ,jacht te paarde" van zes, den „NABOTH en ABIGAëL" van vier andere wevers gekocht. Want ik moet wel aannemen, al had ik meer bijbelvastheid van Haarlemsch vroede vaderen verwacht, dat NABOTH hier voor NABAL staat en wij dus hier Fig. 7 van Oud-Holland XXVIII (I9I0) hebben, dat onverschillig als „DAVIDT en ABIGAEL of als NABAL wordt aangeduid. De rand daar, bij DAMAST, is, ik erken het, ongeveer de zelfde als om het hem toegeschreven land van beloften, waarmee ook de teekening der planten veel overeenkomst heeft.

Men kocht verder de "historie van SuzanNa" van vijf, die van DaNIEl van drie wevers, waaronder beide malen weer QUIRIJN JANSZ gevonden wordt, hoewel hij bij zijn sterven niets meer van dit goed bezat.

De geschiedenis van DANIEL, die wij in 1593 reeds bij PASCHIER LAMERTIJN vonden, bleef mij nog onbekend. Die van Suzanna heb ik reeds in Oud-Holland XXVIII (I9I $)$ blz. 28 beschreven, alleen heb ik mij daar blijkbaar in den tijd vergist en het werk 20 jaar te laat gezet. Al speelt DANIEL ook hier een groote rol, in het naar hem genoemde weefsel zal hij wel de hoofdpersoon zijn.

Al deze damasten kosten, bij $12 / 4$ breedten, niet minder dan 3 gulden, niet meer dan 4 gulden 4 st.; bij het zelfde patroon van verschillende wevers, ja soms van

1) Blijkens de ordonnantie der Staten Generaal van 24 Nov, 1611 (R. Archief. St. Gen. 3277.) Burgemeester RUychaver kreeg 10354 p. I4 st. I2 p. terug. Het verschil zeker ter dekking zijner kosten. Mededeeling van DR. H. E. VAN GELDER.

2) JAQUES LAMBERTYN, damastwerker, die JAQUS LAMMARTjN teekent, komt 5 Jan. I605 in een akte van notaris van Trier te Haarlem als getuige voor.

Oud-Holland, 1913 
den zelfden, verschillen de prijzen, blijkbaar naarmate van de meer of minder fijnte, maar PasChIER LAMERTIJN krijgt twee-, driemaal zooveel. Het komt neer meest op negen en een halve gulden, een enkele maal op $8 \mathrm{gl} .8 \mathrm{st}$.

Dat zijn wel is waar zijn vroegere prijzen bij lange niet en wij vinden hier van hem ook eenvoudiger patronen in het midden als "gesayde bloem" en "banquet", waar hij zijn bijzondere kunst voor de randen schijnt bewaard te hebben, maar de toch altijd nog hooge prijs kan toch nauwlijks alleen aan de fijnte gelegen hebben. Zijn bijzondere kunst is ook hier nog betaald.

"Gesayde bloem" is een bekende groep van patronen, waarvan ik hier vroeger in Fig. I 2 en 13 voorbeelden gaf van $16_{4} 6$ en $16_{54}$ in stijl niet veel verschillend van wat voor LORD THIRLESTONE waarschijnlijk reeds voor I6IO gemaakt werd. Nog eenvoudiger beeldt $\mathrm{H}_{\text {ALS }}$ het af in zijn schuttersstuk van 1616, Fig. 4, in de plaat niet te zien, met nog breederen rand dan het servetje van 1654 met een welkomstgroet, dat jachten rondom heeft.

Maar ook "Banquet" is mij thans niet onbekend meer. Het oudste voorbeeld is, (Victoria and Albert Museum, Photo 32167/795) gemerkt P(AUL) E(LISABETH) M(ASON) I630, Fig. 5, dat ik om den rand, ter zijde geheel dezelfde als van den ORpheus voor het werk van QUIRyn Jansz. DAMAST moet houden, in wiens inventaris het blz. I 3 voorkomt. Latere wijzigingen, zooals er nog zijn, waar zelfs de brandende kandelaars in zijn afgebeeld, komen in het geheel niet in aanmerking. Het hier afgebeelde patroon zou oorspronkelijk van PASCHIER kunnen wezen, maar de rand was hier blijkbaar het voornaamste en wordt het eerste genoemd.

"Gesayde bloemen" komen voor "met te historie van David en Goliath" aan de kanten en eveneens op de kanten "REBECCA en de Samaritaen”, de eene dan waarschijnlijk aan de eene, de ander aan de andere zijde. Hoe breed zulk een rand kan zijn geweest leert ons het schutterstuk van 1616, Fig. 4. Zou deze reiswagen zelfs misschien tot de geschiedenis van den barmhartigen Samaritaan, behoren? De allegorischen figuur wat verder op, hier niet afgebeeld, die een krans ophoudt, vindt echter ook daarbij geen gereede verklaring, maar het lijkt mij daarom toch niet onmogelijk. In ieder geval springt het in het oog dat de schutters van den St. Jorisdoelen een tafellaken van PASCHIER LAMERTIJN hebben gehad. Anderen maakten in dien tijd zulke breede randen niet.

"Banquet" komt met denzelfden rand voor. Deze drie tafellakens hadden "op de eynden de wapens van Vranckrijck en Navarre" Misschien waren zij oorspronkelijk voor HENDRIK IV, in I6IO vermoord, bestemd geweest.

Maar "banquet" vormde ook het middenpatroon van een tafellaken dat moest dienst doen bij twee dozijn servetten "van 't wapen van Nassau", geweven 



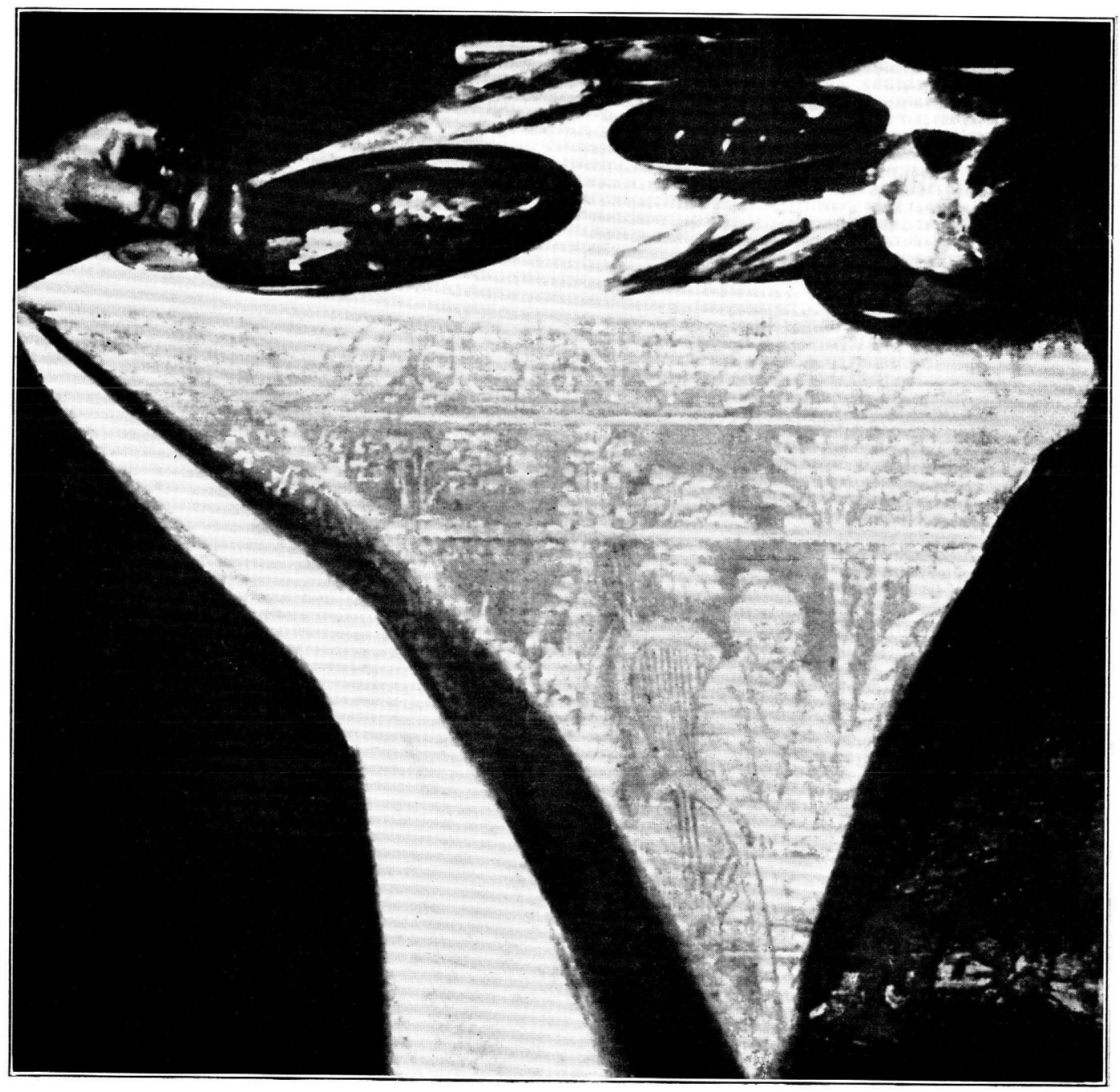

Fig. 4. TAFELLAKEN IN DEN SCHUTTERSMAALTIJD TE HAARLEM, door Frans HaLS geschilderd in 1616. Frans-Hals-Museum te Haarlem. 
"op de canten met galeyen, jachten, schepen, duynen ende anders" geheel in den geest dier servetten dus, terwijl de einden aldus beschreven worden : ...., ,mette afhangende wapenen van Nassau ende Neptunus".

Wat de indeeling van dit patroon betreft, ben ik geneigd aan de wapenen van Nassau in een breeden, aan Neptunus (in effigie) in een tweeden smalleren rand te denken. Een oogenblik heb ik zelfs gedacht dien rand te kennen uit de krabben en visschen van QUIRIJN JANSZ. DAMAST ${ }^{1)}$ maar de onderrand daar lijkt mij toch wat te klein voor een tafellaken van PASCHIER.

Van het volgend jaar, 17 Mei 1612 , is een notarieele verklaring te Haarlem omtrent den prijs die Amsterdamsche kooplieden in 1609 of I6IO aan PASCHIER LAMERTIJN voor soortgelijke weefsels betaald hadden. De prijs was toen nog belangrijk hooger en komt weer op 18 de el van twaalfkwarts breedte.

Hier volgt het stuk dat ik weer aan den heer BREDIUs te danken heb: "Op huyden compareerden voor mij openbaer notaris ende nabeschreven getuygen d'eersame ende seer discreeten JoHAN SAS, coopman ende poorter deser Stadt, out omtrent 58 jaren ende heeft bij sijne mannen waerheyt in plaetse van eede, ten versoecke van PASSCHIER LAMBERTIJN, mr. damastwercker verclaert, ende geaffirmeert warachtich wesen: dat hij den voorn PASSCHIER LAMBERTIJN, requirant, geleden tusschen de drye ende twee jaeren (sonder begrip van den tijt) uyten naeme van Sinjeurs CaSPER van Ceulen ende Gijsbert TheulincX, coopluyden binnen dese Stadt Amsterdamme, omme bij den zelven tot eene vereeringe buyten dese landen versonden te werden, aenbesteet heeft te maecken ende van den zelven voor de voorsz. Sinjeurs CASPER van CEULEN ende Gijsbert Theulincx oock ontfangen heeft, seecker damast ammelaecken van de breete van omtrent drye ellen en de lengte van omtrent ses ellens, daer inne gewrocht was te middewaert een bancket, aen de afthanck ter wedersijden eenige galeyen ende scheepen, enden op de eynden eenige wapenen, mitsgaders noch anderhalve dousijn damaste servietten, yder lanck anderhalve ellen ende breet één elle off daer omtrent, in elcx gewrocht zijnde seeker waepen. Hebbende hij deposant den voorn. PASSCHIER LAMBERTIJN daer vooren betaelt, te weten voor yder elle van 't ammelaecken drye ponden grooten vlaems ende voor elck serviette negen carolus guldens.

(Alles boven 't geen bij de voorn PASSCHIER LAMMERTIJN verschoten ende betaelt was voor de teeckeningh van de voorsz wercken, daer aff hij hem restitutie heeft gedaan sonder de somme preciselijck te hebben onthouden.) ${ }^{2}$ )

1) Het Huis Igor, Pl. XXI.

2) De tusschen haakjes geplaatste woorden zijn in de akte doorgeslagen. 
Offererende ende consenteerende etc. Aldus gedaen binnen Haerlem ten huyse mijns notaris in St. Jansstraete den 17 den Meye anno 1612 in presentie van JAN EGBERTSZ glasemaecker ende PIETER JACOBS cleermaecker als getuygen hiertoe versocht ende met mij notaris gebeden.

In waerheyts oirconden desen bij mij openbaer notaris voornoem bevesticht, W. VAN TRIER, notarius publicus.

Nog eenmaal vinden wij in $16 \mathrm{I}{ }^{1}$ ) hetzelfde patroon bij hem terug in tafellakens "fin fin, thien vierendeelen breed, met landtbouwerie, den affganck, bancquet op tafel, vier bloempotten in de hoeken", maar nu voor slechts 5 p. Io st. de el, wat met een prijs van $12 / 4$ van 6 p. 12 st. overeen zou komen. Wij komen daar nog op terug.

In $16 \mathrm{I}_{3}$ zijn het weer de Staten Generaal, die van hem koopen; 25 April wordt besloten ${ }^{2}$ ) "Te schrijven aan PASSCHIER LAMMERTIJN, damastwercker tot Alckemaer, ende QUIRIJN JANSZ tot Haarlem, bij soo verre sij eenich exquiser goet ende trouw damast ende ander fijn lijnwaet hebben, dat sij hem daermede alhier willen laten vinden, Dinxdage naest commende, om dat hare Hoog Mogende te thoonen."

QUIRIJN JANSZ die, blijkens een akte van notaris VAN TRIER te Haarlem, van 22 Mei 1623, toen omtrent 46 jaar oud was, moet in 1577 geboren, in 1613 dus al 36 jaar zijn geweest, en gold blijkbaar reeds als de eerste damastwever te Haarlem. Voor het bijzonder mooie linnen, dat men voor de "Cheurfurstinne Palsgravinne" wenschte te koopen, kon hij echter tegen zijn mededinger niet op.

Ook in Den Haag werd Ruychaver 30 April met JoACHIMI in deze zaak gecommiteerd en op hun rapport verklarende: "dat de sorteeringe van LAMMERTIJN de bequaemste, beste ende cierlijkste geoordeelt wesende bij luyden daervan verstandt hebbende, omme te vereeren", 4 Mei daertoe gemachtigd, den voorsz LAMMERTIJN genouch verzekert hadden (begerende sijn goet voor eenen redelijcken prijs te vercoopen) dat sij van sijne beste sorteringe souden nemen, ten minste de drye vierendeelen, van de twee middelste sorteringen, tenminste d'ene helft ende van de slechtste een vierde paert", na met hem omtrent den prijs overeengekomen te zijn wat er nog zou blijven van de $f$ 10.000 of $f$ I 2.000 daartoe bestemd, aan Haarlemsche damasten te besteden. ${ }^{3}$ )

Indien de Winterkoningin met zulk een linnenkast tevreden kon zijn, voor LAMERTIJN was het zeker niet minder een buitenkansje. Maar het zou zijn laatste triumph wezen. De „Continuatie van zijn laetste vercregen octroy in 't jaer 1606

1) Dodt van Flensburg. VI, blz. 368.

2) Dodt van Flensburg. V. blz. 274 .

3) Dodt van Flensburg. V. 275 . 



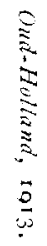

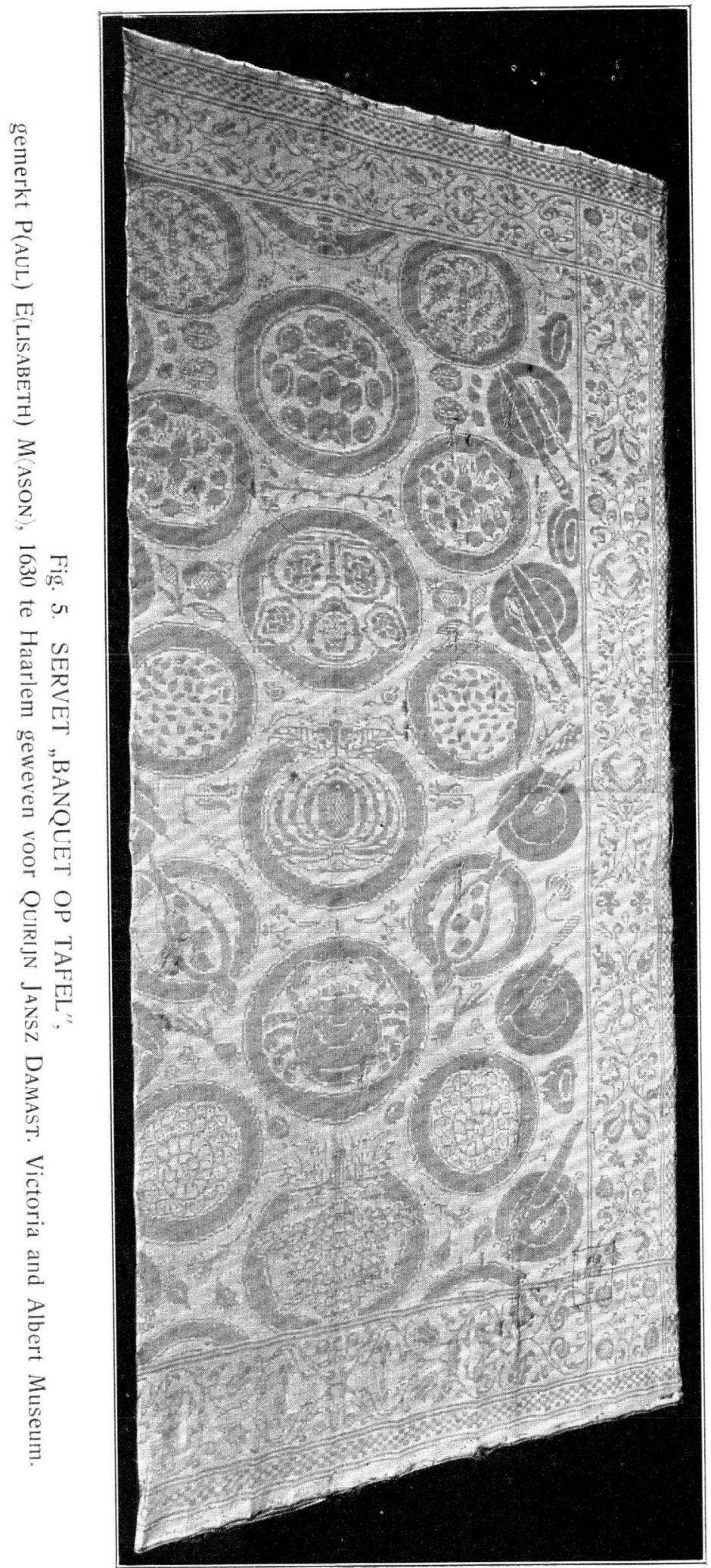


voor noch sess jaeren", waarop bij resolutie van IO Mei I6I31) „advys van die van Haerlem" gevraagd werd "off zij door het accordeeren van de voorsz. versochte continuatie prejuditie souden lijden, mette redenen (ingevalle jae) waerom", werd geweigerd bij besluit van 20 Mei daaraanvolgende. ${ }^{2}$ )

Ook zijn verzoek aan Alkmaar, zijn eersten termijn van $f$ rooo. - met eenig werk te voldoen, wordt 14 September $16{ }_{1} 3$ afgewezen en zijn nader verzoek, 7 December van dat zelfde jaar, eveneens. ${ }^{3}$ )

Betalen kon hij niet en nu biedt hij zijn huis aan ter afdoening ndes stads achterwezen", wat 25 Mei 1614 afgeslagen, maar 29 November toch maar aanvaard wordt. Besloten werd toen het huis "tegen het zeggen van goede mannen te koopen" ten einde "daarvan te winnen en likwideeren" 't geen hij der stad schuldig is ${ }^{3}$ ) en 8 December wordt goedgekeurd de koop voor $f 2700$ vrij geld op 6 Meidagen te betalen. Zoo vindt dan in 1615 de verrekening omtrent het huis en de geleende gelden plaats en heeft hij van Alkmaar niets meer te hopen of te verwachten.

Hij vraagt daarom aan zijn besten klant, de Hoogmogende Heeren, $f$ 2000.ter leen, maar krijgt I5 April I6I5 "nihil" op het request. 4)

Meer geluk heeft hij met een tweede, bescheidener verzoek, waarover de besluiten van 8 , I 2 en 13 Mei 1615 handelen. 5 ) $\mathrm{Na}$ schatting door "twee vrouwen haer des verstaende" worden van damast met "bancquet op tafel", "landtbouwerie" en "blompotten" 8 tafellakens en 22 dozijn bijbehoorende servetten voor 995 gld. Io st. gekocht tegen een prijs die, zooals wij zagen, veel dichter nadert tot den gewonen prijs van damast dan tot wat men hem negen jaar vroeger had betaald.

Dat is het eind, hij verzocht nog een half jaar later ,dat hare Hoog Mogende hem noch zouden willen affcoopen drye dozainen servietten, ten prijse gelijck de voorgaende gecocht zijn", maar zijn verzoek werd afgeslagen den I6en November 16I 5. ${ }^{6}$ )

Verder verluidt niets meer van hem. Pieter Passchiers, damastwerker, dien de Heer BREDIUS in een notarieel stuk van 30 September 1639 te Amsterdam vond (Not. VERBEECK), kan zijn zoon zijn geweest; omtrent het verdere lot van den vader leert ons dit niets.

Hij schijnt met meer uitvinders gemeen gehad te hebben, dat wat hij vond, hoe zeer ook door de tijdgenooten bewonderd, toch door de hooge kosten geen levensvatbaarheid genoeg had om onbeschermd door de wereld te komen. Zijn

1) Dodt van Flensburg, V. 276.

2) Dodt van Flensburg. V. blz. 277.

3) Alkmaarsche Courant 1893 , no. $5 \mathrm{r}$.

4) Dodt van Flensburg. VI. blz. 366.

5) Dodt van Flensburg. VI. blz. 368 .

6) Dodt van Flensburg. VI, blz. $3^{82 .}$ 
meest eigenaardige werk vond zelfs geen navolging. Een patroon als zijn „banquet op tafel" bleef bestaan, maar het heeft niets dat het scherp van het werk van anderen onderscheidt. Zijn randen mogen eenigen invloed uitgeoefend hebben op zulke als van den Orpheus (Oud-Holland I9ro Fig. 3 en 4 ) van de visschen en krabben (Oud-Holland 1910 Fig. 2) en van de gestrooide bloem van I654 (OudHolland 19ro Fig. 13) het eigenlijke kenmerk van zijn werk, het gemis van het spiegelbeeld, dat het patroon voltooit, ontbreekt ook daar.

Wat zonder twijfel, naast de hooge kosten, tot zijn ondergang heeft meegewerkt is, dat er een zekere tegenstrijdigheid niet te miskennen is in wat hij zocht en de eigenste hoedanigheden van het ingewikkelde weefgetouw, waaruit een recht begrip van het patroon een mooi gebruik van dicht en rapport weet te halen, die eenheid aan het geheel geven.

Het is waar, in "gobelin" werk hebben de Chineezen soms een ongewoon leven aan een semis weten te geven, door in plaats van dezelfde vormen nauwkeurig te herhalen, ze telkens lichtelijk te wijzigen. LAMERTIJN zocht in zijn wapens en zijn randen wel iets diergelijks, maar het heeft hem of zijn teekenaar, als hij dien heeft gebruikt, aan den noodigen kunstenaarsaanleg ontbroken, om in die richting iets te bereiken, dat hooger stond dan wat zijn mededingers, met de gedwongen herhaling van de vormen, door den aard van hun werk noodzakelijk, reeds gaven. 